unpublished. It also requires, he considers, historical bibliographies of failures and successes and historical records leading up to and subsequent to them, as well as an intelligent observation of potentialities in regard to the future. These must be expressed to the business man and technologist in brief terse language, so that on straightforward reading he will readily grasp the essentials and be able to indicate to his subordinates and others what he requires in regard to detail. To do this effectively, co-operation, coordination and collaboration with other industrial information sources are essential, and this is the organization we seek.

\section{Books to Read at College}

The Trinity College Bulletin, edited by Prof. H. T. Costello, which comes to us from Hartford, Connecticut, supplies a "List of Books for a College Student's Reading'. This, first published in 1925, has now reached a third, revised edition, and deserves to be popular. The aim of the pamphlet is "to bring the best students and the best books together", helping them to avoid waste of time on inferior stuff. This is an excellent idea in view of the present overcrowded jungle of literature, the reduction of which by the stress of the War will, we hope, be permanent. The general reading course before us is well arranged. The list is divided into ten sections, and students are expected to read and write on something in eight of them. "Reading in the greater classics is likely to get special grade credit." This is as it should be. Early specialization pays to-day and interferes with that versatility which belongs to a liberal education. No censorship of ideas is attempted in the lists, and "books that may shock or annoy" are included. The short descriptions added to each item are expert and helpful.

\section{Meteorites in the Indian Museum}

A CATAlogue of meteorites, with special reference to Indian falls and finds and to specimens in the Indian Museum, Calcutta, has been compiled by A. L. Coulson and published as Memoir 75 of the Geological Survey of India, 1940. An order of the Government of India lays down that all meteorites falling in British India are the property of the Government of India and as such should normally find a place in the Indian Museum under the care of the Geological Survey of India. Every effort is made by the Survey to obtain new falls, and these are carefully studied and the results published in the Records of the Survey.

The first catalogue of the collection was prepared by Thomas Oldham in 1864 and gave particulars of 21 stones and 26 irons. By 1914, when Coggin Brown's catalogue (1916) was compiled, the collection had grown to a total of 379 , though some of the specimens included in this total have since been found to be identical, due to better knowledge of the various synonyms that have been used in the past. Recently there has been active exchange of meteorites with various British and foreign institutions and on August 1, 1939, the collection included 149 irons and 319 stones, a total of 468 falls and finds. The present catalogue deals primarily with Indian falls and finds, but also attempts to include all meteorites, whatever their locality. References to the most important literature dealing with Indian meteorites and a short résumé of the circumstances of fall or find has been given in every case. Other chapters deal with classification, dates of fall or find and geographical distribution.

\section{A New Direction Indicator for an Aeroplane}

According to Science Service, Dr. David Luck has described before the U.S. Institute of Radio Engineers a new form of radio beacon for aeroplanes which has been developed after four years research under his supervision at the laboratory at Central Airport, Camden, N.J. It is called the omnidirectional radio-range beacon, and operates with ultra-highfrequency oscillations to reduce the effect of atmospherics to a minimum. Radio-beacons have been in use for several years, but they serve only to confine the pilot to a definite course. Some air lines have used in addition direction finders to show the direction of the transmitting station from an aeroplane, but these are not satisfactory when using ultra-highfrequencies owing to atmospherics.

Dr. Luck described the operation of the new device as follows. When the pilot has to fly around a portion of his course affected by bad weather, he can always 'see' the direction of the radio-station at a glance. If he wants to fly straight into or out from the beacon, he has only to hold the mark steady, at that course, against a scale on the instrument face. The operation of this indicator may be compared to that of a lighthouse sending out two kinds of light, one a beam which sweeps around steadily and the other a flash sent out in all directions the moment the beam points north. The interval is timed from the flash until the beam sweeps over the observer, and then the required direction from the lighthouse is found. In the new radio device, the radio-lighthouse is on the ground and the indicating instrument on the plane automatically times the flash and beam. All this is done electrically, and the lighthouse beam sweeps round sixty times each second.

\section{Recent Advances in Electroplating}

According to the Electrical Times of August 15, the electroplating of chromium is finding a wide application for purposes other than superficial polish and protection. Recently a German technical paper published an account of the utilization of chromium plating for use with steel cutting tools and bearings. A cheaper grade of steel or even common iron may be employed. The working edge is then plated with chromium, which gives it a hardness comparable to that of diamond. The cutting edge may then be ground, for the chromium may be applied in any thickness, and the tool has all the best features of the hardest and most expensive high-grade steel, its life is multiplied by two or even ten, it wears away far more slowly, and will go through most hard metals as if they were cheese. Bearing journals left 
rather too small as turned out by the lathe may be thickly coated and then turned up to the increased diameter required, thus also cbtaining a skin which lasts a very long time. Worn-down tools, bearings, bushes, gauges, valves, and drills can be rendered better than they were when new.

Similar researches have been made with regard to nickel. All buffing and polishing can now be avoided by using a brightening agent in the electrolyte for plating with this metal. The surface can be taken straight out of the bath directly with all the lustre obtainable by polishing, buffing and tumbling. As these processes involve more work than the electroplating itself, the great advantages of the new method are obvious. Other metals, including chromium, are now the subject of research, and it appears more than probable that a high polish in chromium will shortly be obtainable in the same way. Zine, for example, is already being successfully applied with a high polish on emerging from the bath.

\section{Verifying Telephone Subscribers' Numbers}

To avoid the incorrect recording of callers' numbers in a trunk exchange associated with an automatic telephone area, various expedients have been adopted, including the reversion of a certain percentage of originating calls to the use of an audible tone. The supersonic signal method is described in a paper by W. K. Brasher and B. P. Moss (J. Inst. Elect. Eng., July). It was evolved for Palestine, a country in which the us $\ni$ of a number of languages made the problem more acute. It is usual to check a certain number of demand calls either by establishing a second connexion to the subscriber's line, independent of the first, or by 'reverting' the call, that is, recording the particulars of the required number and informing the caller that he will be rung. Both methods lead to delays. Messrs. Brasher and Moss give a full description with diagrams of the method, which is being evolved in Palestine and is now being installed. Demand positions are served by a $20 \mathrm{kc}$. $/ \mathrm{sec}$. oscillator, the output of which can be connected to the operator's telephone circuit of each position. When the demand operator has received the particulars of the wanted and calling subscribers, she passes the call to the distant exchange and moves a dialling plug suitably. The basic principle of the use of a supersonic signal in an automatic telephone exchange has been proved by test to be a practical scheme, no disturbing effect on other circuits having been noticed in a 5,000-line exchange.

\section{The Night Sky in September}

THE moon is new on September 2, whilst full moon (the harvest moon) occurs on September 16. On September 20 at $21 \mathrm{~h}$. and $23 \mathrm{~h}$. U.T. respectively, the moon is in conjunction with Saturn and with Jupiter. Saturn, to which the moon makes the closer approach, may be rather overpowered by the moon's glare. On September 28, a lunar conjunction occurs with Venus. On September 22, an occultation (reappearance) of the 1st magnitude star $\alpha$ Tauri (Aldebaran) may be observed at the moon's dark limb. At Greenwich the reappearance of Aldebaran, then only $9^{\circ}$ above the horizon, is due at about $22 \mathrm{~h} .3 \mathrm{~m}$.; at Edinburgh, where the altitude is more favourable, the time is $22 \mathrm{~h}$. $16 \mathrm{~m}$., at position angle $215^{\circ}$ from the moon's north point. Jupiter and Saturn continue this month as a notable pair of bright planets to be seen throughout the night. On September 16, Saturn souths at $3 \mathrm{~h} .11 \mathrm{~m}$. and Jupiter at $3 \mathrm{~h} .14 \mathrm{~m}$. (add 1 hour to obtain Summer Time). Close groupings of Jupiter's four inner satellites may be seen at 1 . on September 8, 9, 16, 18, 25 and 26. Venus, unmistakable in its brilliancy, also continues as the bright and morning star rising between $1 \mathrm{~h} .12 \mathrm{~m}$. (September 1) to Ih. 50m. (September 30). On the former date, Venus is about midway between Procyon and Castor and Pollux and by the end of the month has moved to a position preceding Regulus. The darkening evenings of September (the autumnal equinox is on September 23) gives unrivalled aspects, when the moon is absent, of the Milky Way near the meridian. The main features of this half of the great stellar structure are easily recognized - the great rift or bifurcation commencing in Cygnus and extending along the galactic equator: the brighter eastern stream with its various star clouds passing southwards through Aquila, Scutum, Sagittarius to Scorpio, where it is partially united with the broken western stream. More than 100 years ago, Sir John Herschel at the Cape, "rummaging the recesses" of Scorpio, found it full of beautiful globular clusters. It was somewhere here that the elder Herschel found the 'hole' in the heavens, which modern astronomers now recognize as one of the numerous dark nebulæ found in the Milky Way. The Pleiades rise in the late evening as the precursor of winter nights and of brilliant stars in their well-known constellations.

\section{Announcements}

Dr. Paul C. Mangelsdorf, vice-director of the Texas Agricultural Experiment Station, has been appointed professor of botany in Harvard University and assistant director of the Botanical Museum.

Dr. William Cramer, British delegate to the International Cancer Congress at Atlantic City in September 1939 and for more than twenty-five years a member of the Imperial Cancer Research Fund, London, has joined the staff of the Barnard Free Skin and Cancer Hospital in St. Louis.

A FURTHER modification in the terms on which enemy aliens can be released from internment was announced by Sir John Anderson in the House of Commons on August 23. In the White Paper setting out the conditions of release, scientific workers and others with academic qualifications were to be granted release if national work in their special fields was available for them. This qualification is now to be removed, on the recommendation of the Asquith Committee, which pointed out that "the benefits of science and learning were often indirect rather than direct". 